\title{
Effects of Brisk Walking on Plasma Lipoprotein(a), Total Antioxidant Status, Aerobic Fitness, Percent Body Fat, Waist Circumference and Resting Blood Pressure in Overweight and Obese Females
}

\author{
Chen $\mathrm{CK}^{\mathrm{a}}$, Kamarul Hisham NS ${ }^{\mathrm{a}}$, Jeffri $\mathrm{NA}^{\mathrm{a}}$ \\ ${ }^{a}$ Exercise and Sports Science Programme, School of Health Sciences, Universiti Sains Malaysia
}

\begin{abstract}
INTRODUCTION: Obesity is a major public health challenge in many nations including Malaysia. Physical activity has been shown to be a modifiable determinant of obesity and non-communicable diseases. The objective of this study is to investigate the effects of 6 weeks of brisk walking on plasma lipoprotein(a), total antioxidant status, percent body fat, aerobic fitness, waist circumference and resting blood pressure in overweight and obese females.

MATERIALS AND METHODS: Thirty-eight females (Age: $23.2 \pm 3.9$ years BMI: $28.8 \pm 4.5 \mathrm{~kg} . \mathrm{m}^{-2}$ ) were randomly assigned into 2 groups: control $(\mathrm{C})$ and brisk walking $(\mathrm{BW})$ groups. Pre- and post-tests were carried out to measure participants' anthropometric measurements, aerobic fitness, resting blood pressure and blood sample for lipoprotein(a) and total antioxidant levels. Participants in BW group performed the brisk walking exercise, 3 sessions per week for 6 weeks. Participants in $C$ group maintained their sedentary lifestyle and refrained from any other training programme. Results: After 6 weeks of intervention, plasma lipoprotein(a) level was significantly reduced in both $\mathrm{BW}$ and $\mathrm{C}$ groups. There were also significant reductions in waist circumference, percent body fat and resting blood pressure in BW group. However, there were no significant differences in total antioxidant status and aerobic fitness after the brisk walking programme. Conclusion: 6 weeks of brisk walking programme reduces plasma lipoprotein(a), percent body fat, waist circumference and resting blood pressure in overweight and obese females. Therefore, brisk walking is an appropriate exercise to reduce some of the risk factors for noncommunicable diseases among overweight and obese females.
\end{abstract}

KEYWORDS: Brisk walking, Obese, Overweight, Lipoprotein(a), Total antioxidant status

\section{INTRODUCTION}

The Malaysian National Health and Morbidity Survey (NHMS) reported that the prevalence of overweight and obese adults was $30.0 \%$ and $17.7 \%$ respectively. ${ }^{1}$ Obese individuals are likely to have increased risk of numerous

Corresponding Author:

Prof. Dr. Chee Keong Chen

Exercise and Sports Science Programme,

School of Health Sciences,

Universiti Sains Malaysia, Kubang Kerian

16150 Kelantan, Malaysia

Tel No: $+609-7677787$

E-mail : ckchen@usm.my chronic dieases. ${ }^{2,3}$ On the other hand, physical activity has been well-documented as a modifiable determinant of chronic diseases. ${ }^{4}$ Melam and colleagues ${ }^{5}$ have suggested that increased sedentary time and decreased time allocated for physical activities are independently associated with the development of chronic diseases.

Lipoprotein(a) $\mathrm{Lp}(\mathrm{a})$ is a recently accepted biomarker in the field of preventive cardiology. ${ }^{6}$ Current evidence has suggested that $\mathrm{Lp}(\mathrm{a})$ molecules initiate endothelial dysfunction, inflammation and calcification in blood vessels resulting in numerous cardiovascular diseases. ${ }^{6}$ Previous studies have indicated that exercise may reduce 
plasma levels of $\mathrm{Lp}(\mathrm{a}) .7,8$ Nevertheless, physical exercise also initiates the generation of reactive oxygen species (ROS) that may have negative effects on health. However, physically active individuals often display a higher level of adaptation with increased antioxidant defence system and hence are less susceptible to the adverse effects of ROS. ${ }^{9}$

Ogilvie et al. ${ }^{10}$ have described walking as a form of exercise that is most appropriate for individuals who have never engaged in any previous exercise programme. Brisk walking has been highlighted as an underused modality to overcome the problem of obesity in Malaysia since it can be performed with minimal instruction. ${ }^{11}$ Brisk walking appears to meet minimum intensity recommended to achieve cardiorespiratory benefits in sedentary populations. ${ }^{12}$

To our knowledge, studies on the effects of brisk walking on plasma lipoprotein(a), total antioxidant status, aerobic fitness, percent body fat, waist circumference and resting blood pressure in overweight and obese females in Malaysia is scarce. Thus, this study was conducted to investigate the beneficial effects of regular brisk walking among overweight and obese females.

\section{MATERIALS AND METHODS}

\section{Participation's recruitment and experimental design}

Thirty-eight overweight and obese female participants with age ranging between 20 to 35 years old were recruited from the Health Campus of Universiti Sains Malaysia. They were age-matched and randomly assigned into two groups with 19 participants per group: brisk walking group (BW) and control group (C). Participants in the control group were instructed to refrain from any other exercise programme and continued their normal diet. Participants in brisk walking group were required to follow a prescribed brisk walking exercise programme.

Participants were screened in order to determine the inclusion criteria were met. The inclusion criteria to participate in this study were: i) Females between the age of 20-35 years; ii) Body mass index (BMI) within the range from $23.0 \mathrm{~kg} \cdot \mathrm{m}^{-2}$ to $40.0 \mathrm{~kg} . \mathrm{m}^{-2}$; iii) Free from chronic diseases (e.g: cardiovascular diseases, diabetes, cancer and chronic respiratory diseases); iv) Nonsmokers and v) Not engaged in any other physical training programme during the study period. Then, they were asked to complete the participant information and consent form. This study was approved by the Human Research Ethics Committee of Universiti Sains Malaysia (JEPeM Code: USM/JEPeM/16090323).

\section{Brisk walking exercise programme}

Participants in the brisk walking (BW) group were required to perform brisk walking exercise that were conducted three times per week for six weeks. In each exercise session, participants warmed up for five minutes and then started the brisk walking with a distance of 2.2 $\mathrm{km}$, and followed by cooling down activities for five minutes. The brisk walking programme was carried out on the jogging track in the Health Campus of Universiti Sains Malaysia. The researchers supervised and recorded the attendance of the participants during each brisk walking session in order to ensure the compliance to this prescribed exercise programme.

The exercise intensity during this brisk walking programme was set at $55 \%$ to $75 \%$ of the participant's age-predicted maximal heart rate (HRmax). The participants were taught how to count their heart rate by palpation via the carotid or radial pulse immediately after the walking session. The time taken to complete the 2.2 $\mathrm{km}$ walk was between 25 to 35 minutes.

\section{Anthropometric measurements, waist circumference and resting blood pressure}

Anthropometric parameters such as body height and weight were measured during pre-intervention. Body height was measured by using a stadiometer (Seca 220, Germany). Body weight and percent body fat were measured by a body composition analyser (Tanita, model TBF-410, Japan). Waist circumference was measured by using the measuring tape at the narrowest point between ribs and iliac crests and an electronic sphygmomanometer (A\&D Com. Ltd, TM-2540, Japan) was used to measure the resting blood pressure. 


\section{Plasma lipoprotein(a) and total antioxidant status measurements}

At the beginning and end of the study, $5 \mathrm{~mL}$ of resting venous blood sample was drawn from the antecubital vein of the participants after 10 hours of overnight fast. Serum was obtained by centrifuging the blood sample using a centrifuge (Hettich-Rotina 46RS, Germany) for $10 \mathrm{~min}$ at $4000 \mathrm{rpm}$, before being kept at $-20^{\circ} \mathrm{C}$ in a freezer (ThermoForma, Model 705, USA) for subsequent analysis of lipoprotein(a) and total antioxidant levels. Lipoprotein (a) levels were analysed by using Human Lipoprotein (a) ELISA Kit EL3001-1, USA. Total antioxidant status was analysed by using a commercially available kit (QuantiChrom ${ }^{\mathrm{TM}}$ Antioxidant Assay Kit DTAC-100, U. Kingdom).

\section{Aerobic fitness test}

Rockport fitness walking test (RFWT) was used to estimate maximal oxygen uptake $\left(\mathrm{VO}_{2 \max }\right)$ of the participants. The participants were required to walk faster than the normal pace but at steady form for 1mile. At the end of the walk, the heart rate and time to complete the walk was recorded. Participants were reminded to maintain the walking speed throughout the test. Calculation of the estimated $\mathrm{VO}_{2 \max }$ uses the generalised or gender-specific prediction equation using gender, age, weight, time to complete 1-mile walk and heart rate at the end of the walk as predictors. ${ }^{13}$

$\begin{aligned} \mathrm{VO}_{2 \max }\left[\mathrm{ml} . \mathrm{kg}^{-1} \cdot \mathrm{min}^{-1}\right]= & 132.853-0.0769(\mathrm{BW})- \\ & 0.3877(\text { Age })+ \\ & 6.315(\mathrm{Gender})- \\ & 3.2649(\mathrm{~T})-0.1565(\mathrm{HR})\end{aligned}$

Where $B W=$ body weight in pounds; Age measured to the last year;

$$
\begin{aligned}
\text { Gender }= & 0 \text { (female) and } 1 \text { (male); } \\
T= & \text { walk time measured to the nearest bundredth of a } \\
& \text { minute and } \\
H R= & \text { heart rate (beats.min } \left.{ }^{-1}\right) \text { measured immediately at } \\
& \text { the end of the walking test. }
\end{aligned}
$$

\section{STATISTICAL ANALYSIS}

Data were analyzed using the statistical software in the Statistical Package for Social Sciences (SPSS) Version 22.0. All data were expressed as means and standard deviation (SD). Mixed-factorial analysis of variance (ANOVA) was performed to determine the significance of the difference between and within groups. Statistical significance was accepted at $\mathrm{p}<0.05$.

\section{RESULTS}

\section{Anthropometric characteristics of the participants}

Table 1 illustrates the mean age, body weight, body height and body mass index (BMI) of all the participants in this study. There were no significant differences in these parameters between the groups.

Table 1: Mean age, body weight, body height and body mass index (BMI) of the participants

\begin{tabular}{lcc}
\hline Parameters & C group & BW group \\
\hline Age (years) & $23.4 \pm 4.3$ & $23.0 \pm 3.5$ \\
Body weight $(\mathrm{kg})$ & $70.1 \pm 12.8$ & $71.7 \pm 11.7$ \\
Body height $(\mathrm{cm})$ & $156.9 \pm 5.6$ & $156.6 \pm 4.6$ \\
$\begin{array}{l}\text { Body mass index } \\
\left(\mathrm{kg} \cdot \mathrm{m}^{-2}\right)\end{array}$ & $28.4 \pm 4.6$ & $29.2 \pm 4.4$ \\
\hline
\end{tabular}

$\mathrm{C}=$ Control; $\mathrm{BW}=$ Brisk walking

\section{Plasma lipoprotein(a) level}

At pre-test, there were no significant differences $(\mathrm{p}>0.05)$ in lipoprotein(a) level between the groups (C: 154.4 $\mu \mathrm{g} \cdot \mathrm{ml}^{-1}$; BW: $161.8 \mu \mathrm{g} \cdot \mathrm{ml}^{-1}$ ) (Fig. 1A). Similarly, at post-test, there was also no significant difference $(p>0.05)$ in lipoprotein (a) level between the groups (C: $132.7 \mu \mathrm{g} \cdot \mathrm{ml}^{-1}$, BW: $\left.137.5 \mu \mathrm{g} \cdot \mathrm{ml}^{-1}\right)$. After 6 weeks, lipoprotein(a) level was significantly lower at post-test compared to pre-test in $\mathrm{C}$ group $(\mathrm{F}=19.564$, $\mathrm{df}=1$, $\mathrm{p}<0.001)$ and $\mathrm{BW}$ group $(\mathrm{F}=27.365, \mathrm{df}=1, \mathrm{p}<0.001)$. 


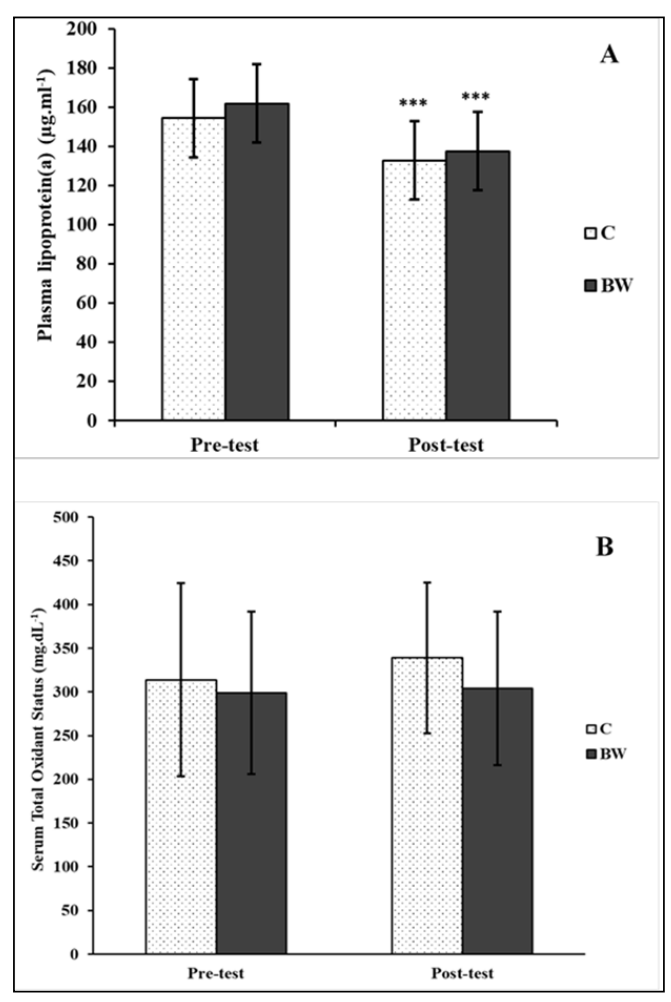

Figure 1(A): Mean lipoprotein(a) levels and (B) total antioxidant status of the participants at Pre- and Post-tests. $* * *$, significantly different from respective pre-test values at $\mathrm{p}<0.001$

\section{Total Antioxidant Status (TAS)}

Mean serum TAS was not significantly different $(\mathrm{p}>0.05)$ between groups at pre-test $(313.92 \pm 110.35$ mg.dL ${ }^{-1}$ vs $299.08 \pm 92.93 \mathrm{mg} \cdot \mathrm{dL}^{-1}$ in the $\mathrm{C}$ and BW groups respectively). At post-test, serum TAS was also not different between groups. After 6 weeks of experimental period, there were no significant changes in serum TAS at post-test compared to its pre-test value for both C and BW groups (Fig. 1B).

\section{Aerobic fitness (Estimated maximal oxygen consumption)}

There were no significant differences $(\mathrm{p}>0.05)$ in mean estimated maximal oxygen consumption between the two groups at pre- and post-tests. After the 6 weeks of experimental period, there were no significant changes in estimated $\mathrm{VO}_{2 \max }$ at post-test compared to pre-test for both C and BW groups (Fig. 2).

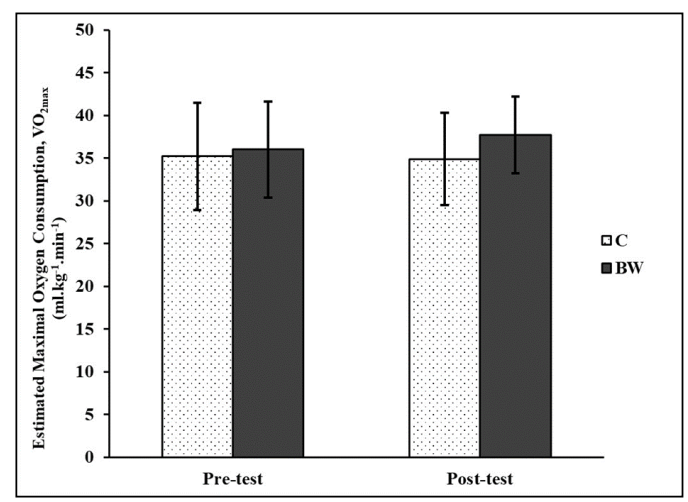

Figure 2: Mean estimated maximal oxygen consumption (VO2max) of the participants at Pre- and Post-tests.

\section{Percent body fat (\%BF)}

Mean percent body fat was not statistically different $(p>0.05)$ between groups at pre- and post-tests. However, after 6 weeks of intervention, percent body fat was significantly lower $(\mathrm{p}<0.01)$ at post-test compared to its pre-test value in the BW group $(43.1 \pm 6.7 \%$ vs $41.5 \pm$ $6.4 \%)$. There were no changes in percent body fat at post-test compared to its pre-test value in the $\mathrm{C}$ group (Fig. 3A).

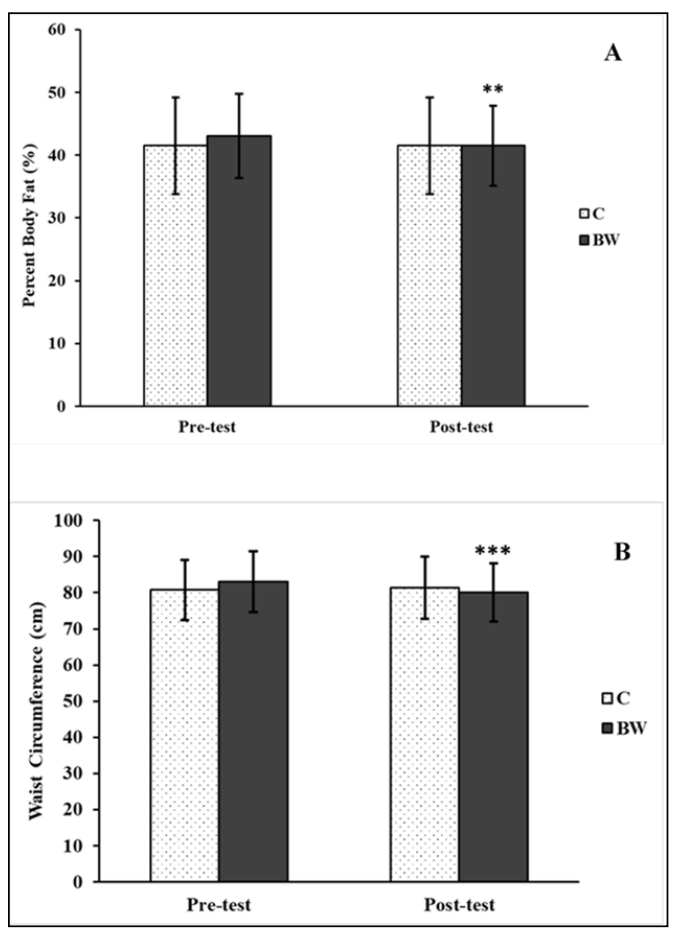

Figure 3(A): Mean percent body fat and (B) waist circumference of the participants at Pre- and Post-tests.

$* *$ significantly different from pre-test at $\mathrm{p}<0.01$

***, significantly different from pre-test at $\mathrm{p}<0.001$ 


\section{Waist Circumference}

At pre-test, there was no significant difference ( $\mathrm{p}>0.05)$ in waist circumference between $\mathrm{C}$ and BW groups (80.8 $\mathrm{cm}$ and $83.1 \mathrm{~cm}$ respectively). At post-test, there was also no significant difference $(\mathrm{p}>0.05)$ between the groups $(81.4 \mathrm{~cm}$ and $80.2 \mathrm{~cm}$ respectively). After 6 weeks of intervention, waist circumference was significantly lower $(\mathrm{F}=32.124, \mathrm{df}=1, \mathrm{p}<0.001)$ at posttest compared to pre-test in the BW group (Fig. 3B). However, this reduction was not observed in the $\mathrm{C}$ group.

\section{Resting Systolic Blood Pressure}

At pre-test, resting systolic blood pressure was not significantly different $(\mathrm{p}>0.05)$ between the groups (C: $120.8 \mathrm{mmHg}$ vs. BW: $118.5 \mathrm{mmHg}$ ). However, resting systolic blood pressure was significantly lower $(\mathrm{F}=6.962$, $\mathrm{df}=1, \mathrm{p}<0.05)$ in the $\mathrm{BW}$ group compared the $\mathrm{C}$ group (110.5 $\mathrm{mmHg}$ vs $118.5 \mathrm{mmHg}$ respectively) at post-test (Fig. 4). After 6 weeks of experimental period, resting systolic blood pressure was significantly lower $(\mathrm{F}=29.074, \mathrm{df}=1, \mathrm{p}<0.001)$ at post-test compared to pretest in BW group (118.5 mmHg vs $110.5 \mathrm{mmHg}$ respectively). This observed reduction in resting systolic blood pressure was not evident in the $\mathrm{C}$ group at posttest.

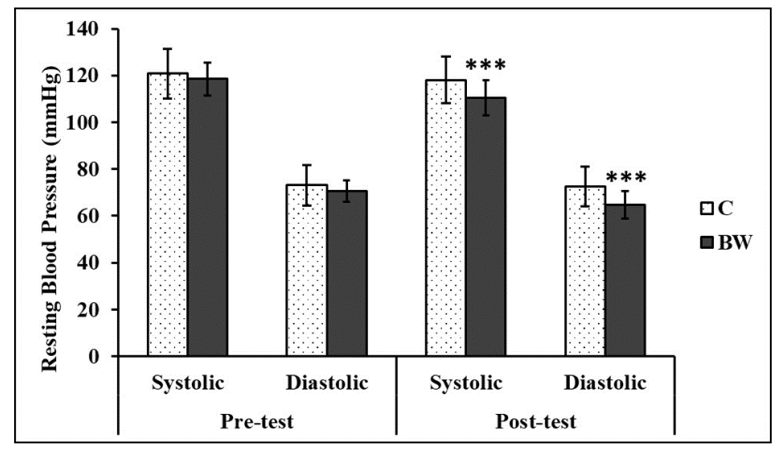

Figure 4: Mean resting blood pressure of the participants at Pre- and Post-tests.

***, significantly different from pre-test at $\mathrm{p}<0.001$

+ , significantly different from $\mathrm{C}$ group at $\mathrm{p}<0.05$

\section{Resting Diastolic Blood Pressure}

There was no significant difference $(p>0.05)$ in resting diastolic blood pressure between the groups (C: 73.1 $\mathrm{mmHg}, \mathrm{BW}: 70.6 \mathrm{mmHg}$ ) at pre-test. However, at post- test, the resting diastolic blood pressure was significantly lower $(\mathrm{F}=11.191, \mathrm{df}=1, \mathrm{p}<0.05)$ in the $\mathrm{BW}$ group compared to the $\mathrm{C}$ group $(64.7 \mathrm{mmHg}$ vs. 72.6 $\mathrm{mmHg}$, respectively) (Fig. 4). After 6 weeks of intervention, resting diastolic blood pressure was significantly lower $(\mathrm{F}=39.813, \mathrm{df}=1, \mathrm{p}<0.001)$ at posttest compared to its pre-test value in the $\mathrm{BW}$ group (64.7 $\mathrm{mmHg}$ vs $70.6 \mathrm{mmHg}$ respectively). This observed reduction in resting diastolic blood pressure was not evident in the $\mathrm{C}$ group at post-test.

\section{DISCUSSION}

\section{Plasma Lipoprotein(a) Level}

Elevated levels of $\operatorname{Lp}(\mathrm{a})$ are associated with increased risk of occlusive vascular disease, especially atherosclerosis. ${ }^{14}$ One of the notable findings of the present study was a significant reduction in lipoprotein (a) level in both control (C) and brisk walking (BW) groups $(p<0.001)$ after 6 weeks of experimental period. However, there was no significant difference between $\mathrm{C}$ and $\mathrm{BW}$ groups at pre- and post-tests.

The significant reduction in plasma lipoprotein(a) in BW group indicated that the prescribed brisk walking programme could be effective in reducing the level of plasma lipoprotein(a). The result of this current study was consistent with the findings of Austin et al. ${ }^{7}$ who reported an exercise-induced decrease in $\mathrm{Lp}$ (a) levels in diabetic adolescents. Rigla et al. ${ }^{8}$ also showed a significant reduction in $\mathrm{Lp}(\mathrm{a})$ levels in diabetic patients after 3 months of physical training.

Our data also showed a significant reduction on plasma Lp(a) level in C group after 6 weeks of experimental period. The most likely explanation for this was that individuals have varied physiological adaptations and intra-variability reactions to $\operatorname{Lp}(\mathrm{a}) .{ }^{15}$

In addition, $\operatorname{Lp}(\mathrm{a})$ levels are largely genetically determined and the broad interindividual variation in $\mathrm{Lp}(\mathrm{a})$ levels is mainly caused by apo(a) size polymorphism. ${ }^{16}$ The other possible reason could be some of the participants in C group were physically active despite being assigned to control group. 
Total antioxidant status (TAS)

Plasma TAS refers to the combined various antioxidant defences and it includes both enzymatic and nonenzymatic systems. A previous study has reported similar findings to our current data as no significant differences were observed between groups in total antioxidant status after 12 weeks of aerobic or strength training. ${ }^{17}$ Similarly, another study has demonstrated that there was no increase in antioxidant levels in untrained individuals after completing 8 weeks of moderate intensity cycling exercise. ${ }^{18}$

However, some previous studies have demonstrated that TAS increases after a bout of exercise or after a training session. A single bout of acute exercise has been shown to increase plasma TAS levels in healthy untrained individuals. ${ }^{19}$ Pilch et al. have reported that 12 weeks of Nordic Walking exercise elicited a significant increase in total antioxidant status among middle-aged women. ${ }^{9}$ Shin et al. ${ }^{20}$ have also shown that 6 months of aerobic endurance training elicited an increase in antioxidant enzyme activities. A probable explanation for the improved antioxidant system following training was attributed to the expression of the genes that regulate the endogenous antioxidant enzymes.

The data from our study showed that there was no change in total antioxidant status after 6 weeks of experimental period. The most likely explanation for this finding could be attributed to the duration of the intervention period that was too short to initiate an antioxidant adaptation to occur.

\section{Aerobic Fitness (Estimated maximal oxygen consumption)}

After 6 weeks of experimental period, there was no significant change in the estimated $\mathrm{VO}_{2 \max }$ of $\mathrm{BW}$ and $\mathrm{C}$ groups. The current findings was similar with other studies which have also shown no improvement in aerobic fitness after a prescribed training programme. Baigis et al. ${ }^{21}$ reported that 15 weeks of home-based exercise for HIV adults had no measurable changes in aerobic fitness. Murtagh et al. ${ }^{22}$ have also shown that 60 min of brisk walking did not improve $\mathrm{VO}_{2 \max }$ in previously sedentary adults. Another recent study also demonstrated that a 10-week intervention of either intermittent walking or continuous walking did not affect the aerobic fitness among sedentary adults. ${ }^{23}$

In contrast to the present findings, there were studies which have shown an improvement in aerobic fitness following a prescribed training programme. Paillard et al. ${ }^{24}$ reported that a brisk walking programme for twelve weeks resulted in a significant improvement in $\mathrm{VO}_{2 \max }$, and loss of fat mass in healthy ageing individuals. Braith et al. ${ }^{25}$ reported that a 3 months walking programme in elderly subjects resulted in an $11 \%$ increase in $\mathrm{VO}_{2 \max }$. Macfarlane et al. ${ }^{26}$ also demonstrated that aerobic fitness improved significantly among sedentary adults following 8 weeks of continuous walking and intermittent walking. Karstoft et al. ${ }^{27}$ also reported that aerobic fitness increases significantly among diabetic patients after performing short bouts of walking.

One of the possible factors for this current finding of no improvement in aerobic fitness of the BW group could be attributed to the short duration of the 6-week programme.

\section{Percent Body Fat}

The present study showed that there was no significant change in percent body fat at post-test compared to pre-test in $\mathrm{C}$ group. However, percent body fat was significantly lower $(\mathrm{p}<0.01)$ at post-test compared to its pre-test value in BW group. The brisk walking routine resulted in a modest, yet statistically significant decrease in percent body fat.

This finding in the present study was in line with the previous studies which demonstrated that regular walking exercise with poles could result in reduced body weight and fat deposits in previously sedentary middleaged women. ${ }^{28,29}$ Recent studies have also provided evidence that Nordic walking decreased percent body fat among post-menopausal women.9,30 A 10-week intermittent or continuous walking interventions resulted in significant reductions in body weight, total fat mass, and body fat percentage among sedentary adults. ${ }^{23}$ In addition, a meta-analysis by Murphy et al. ${ }^{12}$ indicated that studies with well-controlled walking programmes resulted in significant body fat reductions. 
Schjerve et al. ${ }^{17}$ also reported a decrease of $2.2-2.5 \%$ body fat after 12 weeks of moderate or high intensity training. Kostrzewa-Nowak et al. ${ }^{31}$ also reported that after 12 weeks of training, percentage of body fat was significantly decreased in overweight group but no changes were observed among underweight and normal weight individuals. Aerobic training increases energy expenditure via activation of lipolysis and affects the reduction of body weight and body fat percentage. ${ }^{32}$

\section{Waist Circumference}

The present study demonstrated that brisk walking exercise was effective in reducing waist circumference of the overweight and obese participants. The waist circumference was significantly reduced after 6 weeks of intervention period in the BW group. Previous studies have also demonstrated the beneficial effects of brisk walking on waist circumference. A 3-month physical exercise programme resulted in a significant reduction in the waist circumference in diabetic patients. ${ }^{8}$ Another study showed that 12 weeks of brisk walking resulted in a significant decrease in waist circumference among obese males. ${ }^{33}$ In addition, Melam et al. $^{5}$ showed that waist circumference among 45 overweight women reduced significantly following 10 weeks of aerobic and brisk walking. Hence, the present study and study of Melam et al. ${ }^{5}$ findings imply that brisk walking was effective in reducing waist circumference.

\section{Resting Blood Pressure}

The resting systolic and diastolic blood pressure (BP) was significantly reduced from pre-test to post-test in BW group after 6 weeks of intervention. However, this observation was not evident in the $\mathrm{C}$ group. Chaudhary et al. ${ }^{34}$ also showed that there was a significant reduction in both resting systolic and diastolic blood pressure after aerobic training. Thus, the results of both these studies showed a similar finding where resting blood pressure was significantly reduced after 6 weeks of aerobic exercise.

In contrast with the data from the present study, another study employing greater walking volumes ${ }^{35}$ have demonstrated that there were no significant changes in blood pressure. In addition, previous walking studies which have used participants with BP less than 129/84 $\mathrm{mm} \mathrm{Hg}$, have reported non-significant changes in systolic BP or diastolic BP.22,35 The plausible reasons for the different effects of walking on blood pressure in these studies could be attributed to the different exercise intensity, gender of the participants and adherence of the participants to the prescribed walking programmes.

\section{CONCLUSION}

Our results demonstrated that 6 weeks of brisk walking exercise, 3 sessions per week with intensity $55 \%-75 \%$ of maximum heart rate seems to reduce plasma lipoprotein (a) level, percent body fat, waist circumference and resting blood pressure in overweight and obese females. In conclusion, the prescribed brisk walking appears to be adequate to elicit improvements in some of the cardiovascular risk factors in overweight and obese females. Nevertheless, more studies with longer duration or frequency or different exercise intensities are warranted to determine the beneficial effects of brisk walking on total antioxidant status and aerobic fitness among these individuals.

\section{ACKNOWLEDGEMENT}

We wish to express our sincere gratitude to all the participants who have participated in this study. This study was funded by an Exercise Medicine Research Grant (EMRG) (Grant No: EMRG/2018/18001) provided by Monspace Multi-National Corporation. The authors also wish to thank all staff of the Exercise and Sport Science Programme, USM, especially Mdm.Jama'ayah Meor Osman, Madam. Norlida Azalan and Madam Nurul Ain Fathma Abdullah for their technical assistance.

\section{CONFLICT OF INTEREST}

The authors declare that there is no conflict of interest.

\section{REFERENCES}

1. Institute for Public Health (IPH). National Health and Morbidity Survey 2015 (NHMS 2015). Vol. II: Non-Communicable Diseases, Risk Factors \& Other Health Problems; 2015. 
2. Wan Mohamud WN, Musa KI, Md Khir AS, Ismail AA, Ismail IS, Kadir KA, et. al. Prevalence of overweight and obesity among adult Malaysians: an update. Asia Pac J Clin Nutr. 2011;20(1):35-41.

3. De Lorenzo A, Gratteri S, Gualtieri P, Cammarano A, Bertucci P, Di Renzo L. Why primary obesity is a disease? J Transl Med. 2019; 17:169.

4. Ho SS, Dhaliwal SS, Hills AP, Pal S. The effect of 12 weeks of aerobic, resistance or combination exercise training on cardiovascular risk factors in the overweight and obese in a randomized trial. BMC Public Health. 2012;12 (1):704.

5. Melam GR, Alhusaini AA, Buragadda S, Kaur T, Khan IA. Impact of brisk walking and aerobics in overweight women. J Phys Ther Sci. 2016;28 (1):293-7.

6. Wilson DP, Jacobson TA, Jones PH, Koschinsky ML, McNeal CJ, Nordestgaard BG, et. al. Use of Lipoprotein (a) in clinical practice: A biomarker whose time has come. A scientific statement from the National Lipid Association. J Clin Lipidol. 2019;13(3):374-92.

7. Austin A, Warty V, Janosky J, Arslanian S. The relationship of physical fitness to lipid and lipoprotein (a) levels in adolescents with IDDM. Diabetes Care. 1993;16(2):421-5.

8. Rigla M, Sánchez-Quesada JL, Ordóñez-Llanos J, Prat T, Caixàs A, Jorba $\mathrm{O}$, et. al. Effect of physical exercise on lipoprotein (a) and lowdensity lipoprotein modifications in type 1 and type 2 diabetic patients. Metabolism. 2000;49 (5):640-7.

9. Pilch W, Tota , Piotrowska A, Śliwicka E, Czerwińska-Ledwig O, Zuziak R, et. al. Effects of nordic walking on oxidant and antioxidant status: levels of calcidiol and proinflammatory cytokines in middle-aged women. Oxid Med Cell Longev. 2018; 6468234.

10. Ogilvie D, Foster CE, Rothnie H, Cavill N, Hamilton V, Fitzsimons CF, et. al. Interventions to promote walking: systematic review. Bmj. 2007;334(7605):1204.

11. Chen CK. Brisk walking the underused modality to alleviate obesity. J Obes Weight Loss Ther. 2014;4:e112.
12. Murphy MH, Nevill AM, Murtagh EM, Holder, RL. The effect of walking on fitness, fatness and resting blood pressure: a meta-analysis of randomised, controlled trials. J Prev Med, 2007;44(5): 377-385.

13. Kline CJ, Porcari JP, Hintermeister R, Freedson PS, Ward A, McCarron RF, et. al. Estimation of from a one-mile track walk, gender, age and body weight. Med. Sci. Sports Exerc. 1987;19:253-9.

14. Holme I, Urdal P, Anderssen S, Hjermann I. Exercise-induced increase in lipoprotein (a). Atherosclerosis. 1996;122(1):97-104.

15. Mackness M, Hughes E. Variability in the measurement of lipoprotein (a) in the British Isles. Ann. Clin. Biochem. 2009;46(4):311-5.

16. Austin MA, Sandholzer C, Selby JV, Newman B, Krauss RM, Utermann G. Lipoprotein (a) in women twins: heritability and relationship to apolipoprotein (a) phenotypes. Am. J. Hum. Genet. 1992;51(4):829.

17. Schjerve IE, Tyldum GA, Tjønna AE, Stølen T, Loennechen JP, Hansen HE, et. al. Both aerobic endurance and strength training programmes improve cardiovascular health in obese adults. Clin Sci. 2008;115(9):283-93.

18. Tiidus PM, Pushkarenko JO, Houston ME. Lack of antioxidant adaptation to short-term aerobic training in human muscle. Am. J. Physiol. Regul. Integr. Comp. Physiol. 1996;271(4):R832-6.

19. Berzosa C, Cebrian I, Fuentes-Broto L, GómezTrullén E, Piedrafita E, Martínez-Ballarín E, et. al. Acute exercise increases plasma total antioxidant status and antioxidant enzyme activities in untrained men. Biomed Res. Int. 2011; Article ID 540458.

20. Shin YA, Lee JH, Song W, Jun TW. Exercise training improves the antioxidant enzyme activity with no changes of telomere length. Mech Ageing Dev. 2008;129(5):254-60.

21. Baigis J, Korniewicz DM, Chase G, Butz A, Jacobson D, Wu AW. Effectiveness of a homebased exercise intervention for HIV-infected adults: a randomized trial. J Assoc Nurse Aids C. 2002;13(2):33-45.

22. Murtagh EM, Boreham CA, Nevill A, Hare LG, Murphy MH. The effects of 60 minutes of brisk walking per week, accumulated in two different patterns, on cardiovascular risk. J Prev Med. 
2005;41(1):92-7.

23. Rodriguez-Hernandez MG, Wadsworth DW. The effect of 2 walking programs on aerobic fitness, body composition, and physical activity in sedentary office employees. PloS One. 2019;14(1). e0210447.

24. Paillard T, Lafont C, Costes-Salon MC, Riviere D, Dupui P. Effects of brisk walking on static and dynamic balance, locomotion, body composition, and aerobic capacity in ageing healthy active men. Int J Sports Med. 2004;25(07):539-46.

25. Braith RW, Pollock ML, Lowenthal DT, Graves JE, Limacher MC. Moderate-and high-intensity exercise lowers blood pressure in normotensive subjects 60 to 79 years of age. Am J Cardiol. 1994;73(15):1124-8.

26. Macfarlane DJ, Taylor LH, Cuddihy TF. Very short intermittent vs continuous bouts of activity in sedentary adults. J Prev Med. 2006;43(4):332-6.

27. Karstoft K, Winding K, Knudsen SH, Nielsen JS, Thomsen C, Pedersen BK, et. al. The effects of free-living interval-walking training on glycemic control, body composition, and physical fitness in type 2 diabetic patients: a randomized, controlled trial. Diabetes Care. 2013;36(2):228-36.

28. Mikalacki M, Radjo I, Cokorilo N, Korovljev D, Smajic M. Influence of Nordic walking on body composition of elderly women. Health Med. 2012;6(2):476-82.

29. Jasiński R, Socha M, Sitko L, Kubicka K, Woźniewski M, Sobiech KA. Effect of nordic walking and water aerobics training on body composition and the blood flow in lower extremities in elderly women. J Hum Kinet. 2015;45(1):113-22.

30. Cebula A, Tyka AK, Pilch W, Szygula Z, Palka T, Sztafa-Cabala K, et. al. Effects of 6-week Nordic walking training on body composition and antioxidant status for women> 55 years of age. Int J Occup Med Env. 2017;30(3):445-454.

31. Kostrzewa-Nowak D, Nowak R, Jastrzębski Z, Zarębska A, Bichowska M, Drobnik-Kozakiewicz I, et. al. Effect of 12-week-long aerobic training programme on body composition, aerobic capacity, complete blood count and blood lipid profile among young women. Biochem Medica. 2015;25(1):103-13.
32. Kravitz L. Resistance training: Adaptations and health implications. Idea Today. 1996;14:38-49.

33. Azeem K. Effect of twelve weeks brisk walking on blood pressure, body mass index, and anthropometric circumference of obese males. Int J Med Health Biomed Bioengineer Pharma Engineer. 2011;5(11):530-2.

34. Chaudhary S, Kang MK, Sandhu JS. The effects of aerobic versus resistance training on cardiovascular fitness in obese sedentary females. Asian J Sports Med. 2010;1(4):177-184.

35. Murphy MH, Hardman AE. Training effects of short and long bouts of brisk walking in sedentary women. Med Sci Sports Exerc.1998;30 (1):152-7. 